\title{
ESPOROS BACTERIANOS PARA EL TRATAMIENTO DEL CÁNCER.
}

\section{BACTERIAL SPORES A CANCER TREATMENT.}

\section{Begoña Rodríguez González, Elena Ruiz Lencioni, Laura Romero Jiménez y Ma Teresa Cutuli de Simón.}

Departamento de Sanidad Animal. Facultad de Veterinaria. UCM

Correspondencia del autor: mtcutuli@vet.ucm.es

\section{RESUMEN}

Los métodos utilizados actualmente en el tratamiento del cáncer son todavía muy lesivos para el organismo y en muchas ocasiones poco efectivos. Los tumores sólidos con zonas de hipoxia presentan los mayores inconvenientes para su resolución. En las investigaciones sobre alternativas para su tratamiento, son muchos científicos los que apuestan por el uso de bacterias y por sus formas de resistencia, los esporos.

Diferentes investigaciones realizadas han comprobado las ventajas del empleo de esporos bacterianos (Clostridium novyi-NT, Clostridium sporogenes ATCC13732, y Clostridium beijerinckii NCIMB 8052). Se caracterizan por ser estables hasta alcanzar zonas con las condiciones concretas permisivas para su germinación (hipoxia), por lo que pueden ser administrados por vía sistémica. El efecto antitumoral producido se basa en la producción de enzimas hidrolíticas (proteasas, nucleasas y lipasas) y, en la competición entre la bacteria y las células neoplásicas por los nutrientes. Así mismo, mediante técnicas de modificación del genoma, se han podido suprimir los genes perjudiciales e insertar diversos genes y plásmidos terapéuticos de acción selectiva en el tumor. Y por último, pueden combinarse con otros tratamientos (COBALT combination bacteriolytic therapy).

El uso de esporos modificados genéticamente supone un nuevo horizonte en el tratamiento del cáncer, sobre todo en regiones inaccesibles del tumor.

Palabras clave: esporos, cáncer, Clostridium novyi -NT, 


\begin{abstract}
Currently, cancer treatment methods used are still very harmful for the body and often ineffective. The resolution of solids tumors with hypoxia zones has major disadvantages. There are many scientists who opt for the use of bacteria and their forms of resistance, the spores, as treatment alternatives. Different studies have confirmed the advantages of the use of bacterial spores (Clostridium novyi-NT, Clostridium sporogenes ATCC13732, and Clostridium beijerinckii NCIMB 8052). These are stable till they reach areas with the permissive concrete conditions for germination (hypoxia), and can be administered by systemic route. The antitumor effect is based on the hydrolytic enzymes production (proteases, nucleases and lipases) and a nutritional competition between bacterium and neoplastic cells. Using genome modification techniques deleterious genes have been removed and others to improve their effectiveness have been inserted. And finally, they can be combined with other treatments (COBALT combination bacteriolytic therapy).

The use of genetic modified spores represents a new horizon in cancer treatment, especially in inaccessible regions of the tumor.
\end{abstract}

Key woks: spores, cancer, Clostridium novyi -NT,

\title{
1. INTRODUCCIÓN:
}

Hoy en día las terapias contra el cáncer son aún muy lesivas y de dudosa eficacia, a lo que hay que añadir la resistencia a los tratamientos convencionales. Por estos motivos se han multiplicado los estudios que intentan abordar horizontes inéditos, que incluyen nuevas terapias alternativas para paliar esta enfermedad.

Dentro de los distintos tipos de tumores, los sólidos con zonas de hipoxia presentan los mayores inconvenientes para su resolución. En las investigaciones sobre alternativas para el tratamiento, son muchos científicos los que apuestan por el uso de bacterias y por sus formas de resistencia, los esporos. En el presente trabajo realizamos una pequeña revisión sobre conceptos e investigaciones que emplean dicha terapia como tratamiento del cáncer.

\section{TUMORES SÓLIDOS:}

De los tumores diagnosticados, más de un 90\% resultan ser tumores sólidos. Recientes investigaciones han arrojado luz sobre su fisiopatología, antes desconocida, ya que poseen peculiaridades que los hacen característicos.

Este tipo de neoplasias crea un microambiente caracterizado por una vascularización heterogénea, que provoca la aparición de grandes regiones en las que la presión parcial de oxígeno es baja. Estas condiciones, inducen modificaciones en el metabolismo celular, así 
como selección de células resistentes a la apoptosis y modificaciones epigenéticas que en ocasiones son causa de quimiorresistencia ante los tratamientos tradicionales.

\section{$\checkmark \quad$ NEOVASCULARIZACIÓN TUMORAL:}

La neoangiogénesis es esencial para el crecimiento tumoral, e indicativo de su malignidad. Esta neovascularización genera vasos anormales y como la tasa de proliferación de las células neoplásicas es mayor que la de la neoformación endotelial, da como resultado una insuficiente irrigación del tumor y por tanto aparecen grandes regiones hipóxicas, Trédan et al., (2007).

En efecto, los nuevos vasos sanguíneos presentan mayor heterogeneidad y una estructura anormal (grandes fenestraciones, ausencia de membrana basal y largas uniones interendoteliales). Son vasos flexuosos, dilatados en los que aparecen shunts arteriolovenulares y fondos de saco.

Las células tumorales en su sobrecrecimiento anormal, son capaces de comprimir y ocluir los vasos, subsiguiendo una vascularización caótica e ineficiente, tanto espacial como temporalmente, siendo variable incluso dentro de las distintas regiones del tumor, generando la hipoxia (Fig. 1).

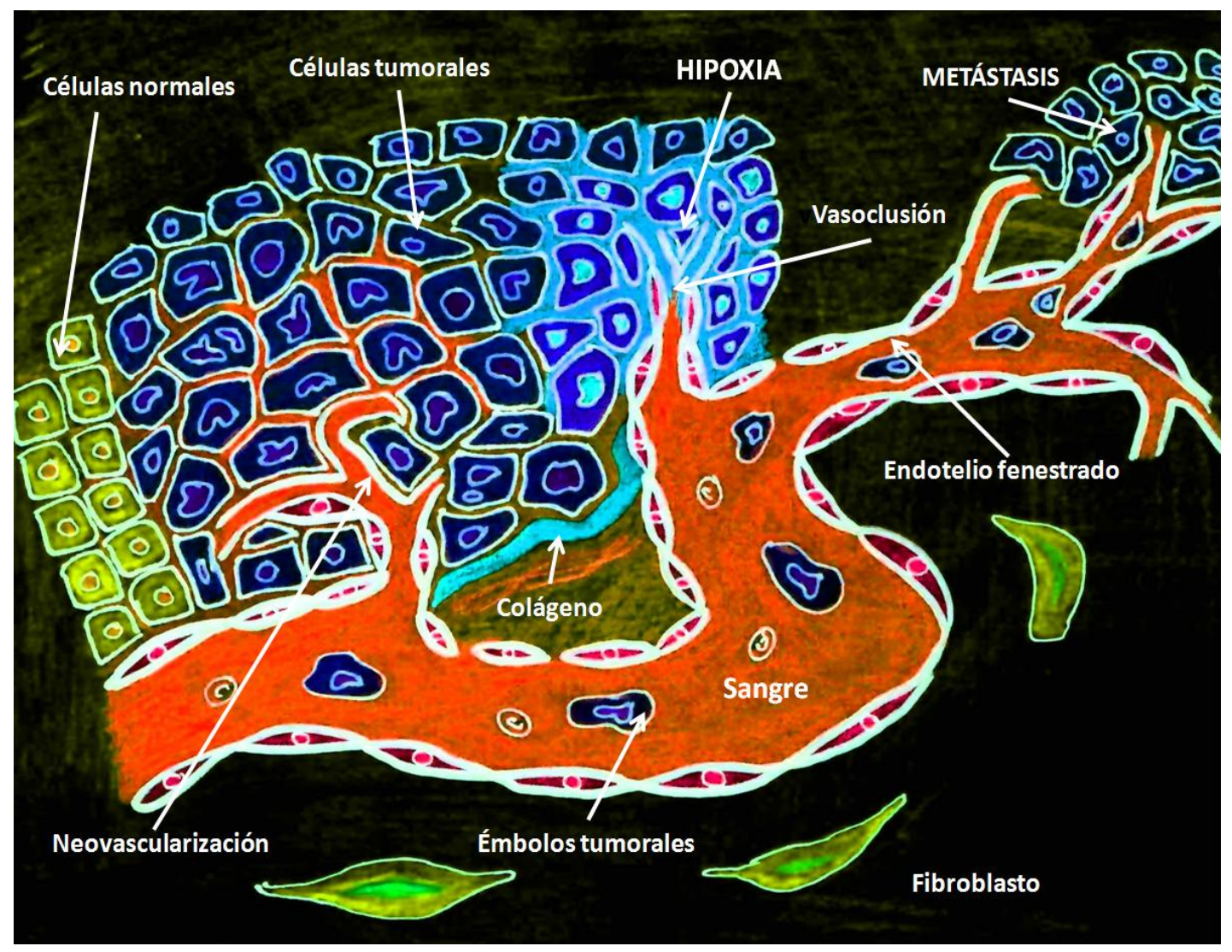

Figura 1: Neoangiogénesis tumoral. Proceso ineficiente, en donde los fenómenos vasoclusivos generan zonas hipóxicas y las células neoplásicas se embolizan dando lugar a metástasis. 


\section{HIPOXIA TUMORAL}

Las zonas hipóxicas son reconocidas en la mayoría de los tumores de tamaño grande $(\geq 10$ $\mathrm{mm})$; Trédan et al. (2007) señalan que los pequeños tumores $(\leq 1 \mathrm{~mm})$ son igualmente vascularizados de forma insuficiente y presentan zonas hipóxicas y necróticas. A pesar de la existencia de neovasos, no se garantiza la buena oxigenación debido a interrupciones temporales en el flujo por compresión y fenómenos vasoclusivos.

Las necesidades energéticas de las células neoplásicas son entre 100 y 400 veces superiores a las de células no cancerosas. Esta privación de nutrientes, además de la de oxígeno, induce cambios en las poblaciones celulares, en su aprovechamiento energético y metabolismo oxidativo, favoreciendo la aparición de fenotipos agresivos y resistentes a condiciones hostiles, Kizaka-Kondoh et al., (2008).

Las células tumorales en condiciones de hipoxia presentan una inestabilidad genómica que altera la expresión post-transcripcional. Entre los cambios que se producen podemos destacar la sobreexpresión de HIF-1 (Hypoxia-inducible transcription Factor 1), que activa vías de señalización que permiten a la célula cancerosa adoptar una respuesta adaptativa a la hipoxia Trédan et al., (2008); Wei et al., (2007). Entre dichas respuestas se encuentra la activación de más de 50 genes que codifican factores proteicos implicados en la neoangiogénesis, como el VEGF (Vascular Endotelial Growth Factor) o FGF (Fibroblast Growth Factor) con consecuencias como la formación de neovasos y modificaciones de la matriz extracelular (Fig.2).

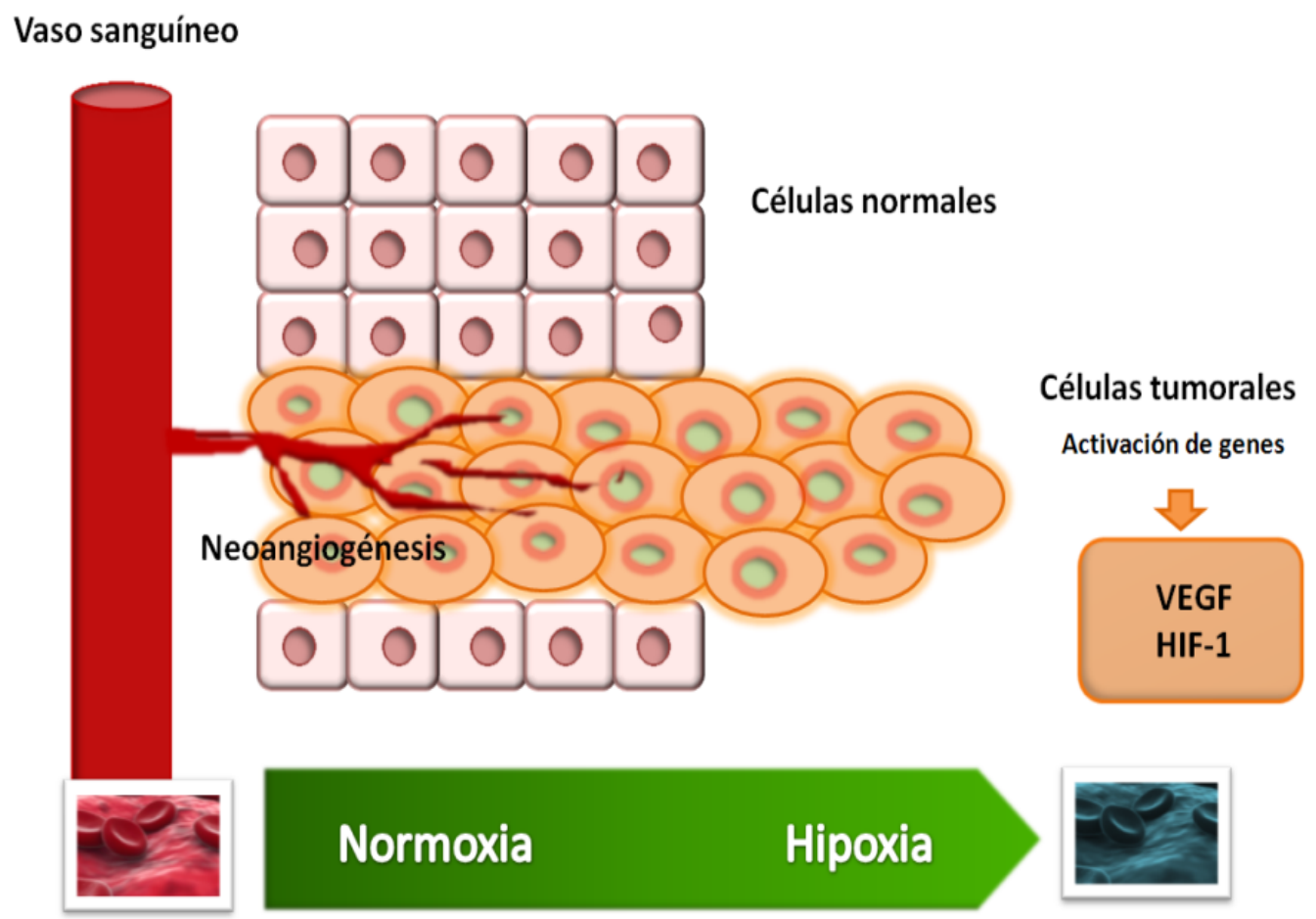

Figura 2: Las células neoplásicas en su sobrecrecimiento anormal son vascularizadas insuficientemente, produciéndose la hipoxia, y, como respuesta a la misma, fenómenos adaptativos como la sobreexpresión de HIF-1 (Hypoxia-inducible transcription Factor 1) o de VEGF (Vascular Endotelial Growth Factor). 


\section{$\checkmark \quad$ PROBLEMÁTICA DE LOS TUMORES SÓLIDOS}

La angiogénesis es un factor que influye decisivamente en la metastatización tumoral, favoreciendo la embolización de células neoplásicas a regiones distantes del foco primario del tumor. Este factor constituye un serio problema a la hora de abordar los tumores sólidos, Wei et al., (2007).

Otro factor que determina la problemática de los tumores sólidos es la quimiorresistencia y la radiorresistencia, Brown, (2002). El entorno tumoral posee una presión elevada en el líquido intersticial debida a la estructura porosa de los vasos, la salida de macromoléculas y a la ausencia de vasos linfáticos funcionales. La presión intersticial elevada disminuye los movimientos convectivos. Esto interfiere en los tratamientos quimioterápicos, impidiendo o dificultando la entrada de agentes anticancerosos a través de un tejido rico en colágeno y con elevada densidad celular como es el tumor, obstaculizando que las regiones tumorales sean expuestas a dosis letales de quimioterápicos.

Hay que señalar también, que la hipoxia por sí misma es un factor de quimiorresistencia y limita la eficacia de los fármacos quimioterápicos; también disminuye la sensibilidad de las células neoplásicas a la apoptosis y aumenta la frecuencia de aparición de fenotipos multirresistentes (MDR).

Todo lo expuesto es la base para comprender las dificultades que presentan las terapias convencionales en la penetración a las zonas hipóxicas del tumor, y lleva a pensar en un agente capaz de acceder a dichas regiones. Ese agente capaz de convertir en dianas las zonas potencialmente problemáticas de los tumores sólidos podría ser un microorganismo.

\section{UTILIZACIÓN DE MICROORGANISMOS EN EL TRATAMIENTO DE TUMORES SÓLIDOS.}

No es una cuestión reciente plantearse utilizar un microorganismo en el tratamiento de tumores. Esta idea aparece ya en el siglo XIX. En un principio, no se trató del uso deliberado de los microorganismos para tratar la enfermedad, sino que, de manera fortuita, se observó en pacientes con cáncer, que tras una infección bacteriana experimentaban una remisión del tumor. Por lo que se empezó a pensar en la posible relación entre el agente causante de la infección y la mejoría.

Una serie de estudios experimentales dieron resultados que merecía la pena cuestionar. En 1813 Vautier comprobó, accidentalmente, que pacientes que padecían cáncer y habían desarrollado gangrena gaseosa por una infección con Clostrididum perfringens mejoraban, observándose en ellos una regresión del tumor que sugería estar relacionada con la bacteria, Wei et al., (2008a). En 1868 el físico alemán W. Busch indujo una infección por Streptococcus pyogenes en una paciente con cáncer, poniéndola en una cama previamente ocupada por un paciente que padecía erisipela, observando una mejoría. La mujer murió nueve días después a causa de la infección bacteriana. Casi 30 años después William B. Coley observó la remisión de un tumor en otro paciente que padecía erisipela. Estudios similares se 
dieron en Europa cuando Friedrich Fehleisen, además de identificar a S.pyogenes como la causa de la erisipela, empezó a utilizar las bacterias como método curativo, Wei et al., (2007).

Estos resultados han fomentado la investigación que intenta determinar si las bacterias pueden inducir efectos antitumorales, y por consiguiente, ser utilizadas deliberadamente para el tratamiento del cáncer, y si es así, qué tipo de bacterias son las que producen tales efectos, y cuáles son sus mecanismos.

\section{TIPOS DE BACTERIAS SUSCEPTIBLES A SER UTILIZADAS EN TRATAMIENTOS ANTITUMORALES.}

Las bacterias pueden inducir efectos antitumorales de distintas maneras, bien mediante la producción de toxinas o enzimas que causan efectos citotóxicos, o como vectores de genes terapéuticos (previa modificación genética). Para producir sus efectos es necesario que sean administradas en el tumor y alcancen las células neoplásicas para producir oncolisis. Por tanto, las bacterias ideales para llevar a cabo esta misión deben ser genéticamente modificables, no patógenas y tolerables por el hospedador. Así mismo, mostrar preferente replicación y acumulación en presencia de tumores, tener baja inmunogenicidad, y ser susceptibles a ser eliminadas mediante antibióticos. Por último, deben poder ser administradas sistémicamente y no tener efectos nocivos sobre los tejidos sanos, Ryan et al., (2005).

Entre las bacterias que cumplen un buen número de estos requisitos se encuentran las bacterias anaerobias estrictas y facultativas, y mención especial merecen las bacterias formadoras de esporos. Estas bacterias anaerobias cuentan con la particularidad de replicarse en zonas con baja tensión de $\mathrm{O}_{2} \mathrm{o}$ en condiciones de hipoxia. El tumor provee de un nicho ecológico dónde podemos explotar zonas hipóxicas y anóxicas. Además en el caso de las anaerobias estrictas se impide el crecimiento bacteriano en tejidos no neoplásicos (carentes de zonas hipóxicas).

\section{- ANAEROBIAS FACULTATIVAS:}

Estas bacterias pueden multiplicarse en presencia o en ausencia de oxígeno. Las más estudiadas pertenecen al grupo gram negativas, en concreto especies dentro del género Salmonella spp (S. typhimurium), Leschner y Weiss, (2010). Ahora bien, aunque Salmonella typhimurium tiene la propiedad de colonizar zonas hipóxicas de tumores de diversos tamaños, su uso está muy limitado en la terapia anticancerosa por el peligro que supone la invasión de zonas no cancerosas, al ser anaerobia facultativa y además presentar carácter de patógeno intracelular, Wei et al., (2008b).

\section{- ANAEROBIAS OBLIGADAS:}

No requieren oxigeno para su crecimiento y tampoco son capaces de tolerarlo. Dado que sólo pueden replicarse en condiciones de hipoxia, su acumulación se restringe a estas áreas del tumor. Entre este grupo bacteriano los géneros Bifidobacterium spp. y Clostridium spp. son los más destacados. 
Las especies del género Bifidobacterium spp. no son patógenas y forman parte de la flora intestinal en humanos y mamíferos, presentando la característica de actuar como probióticos, Taniguchi et al., (2010), Kim et al., (2002), Yazawa et al., (2000). Ahora bien, son poco estables en condiciones no permisivas y de difícil almacenamiento.

Sin duda las especies del género Clostridium spp. son unas de las más investigadas, tanto aquéllas que tienen capacidad patógena, como las que no; entre estas últimas las más estudiadas son $C$. histoliticum, C. butyricum y $C$ novyi NT. Todas ellas poseen la extraordinaria característica de formar esporos, o formas de resistencia, que es de fundamental importancia en gran número de investigaciones, y además presentan la posibilidad de soportar ciertas condiciones no permisivas, Liu et al., (2002), Fox et al., (1996).

En la figura 3 del texto hemos tratado de exponer y esquematizar la estrategia y los resultados obtenidos de distintos estudios, realizados con los géneros anteriormente comentados, que han sido objeto de investigación en la terapia antitumoral (Fig. 3)
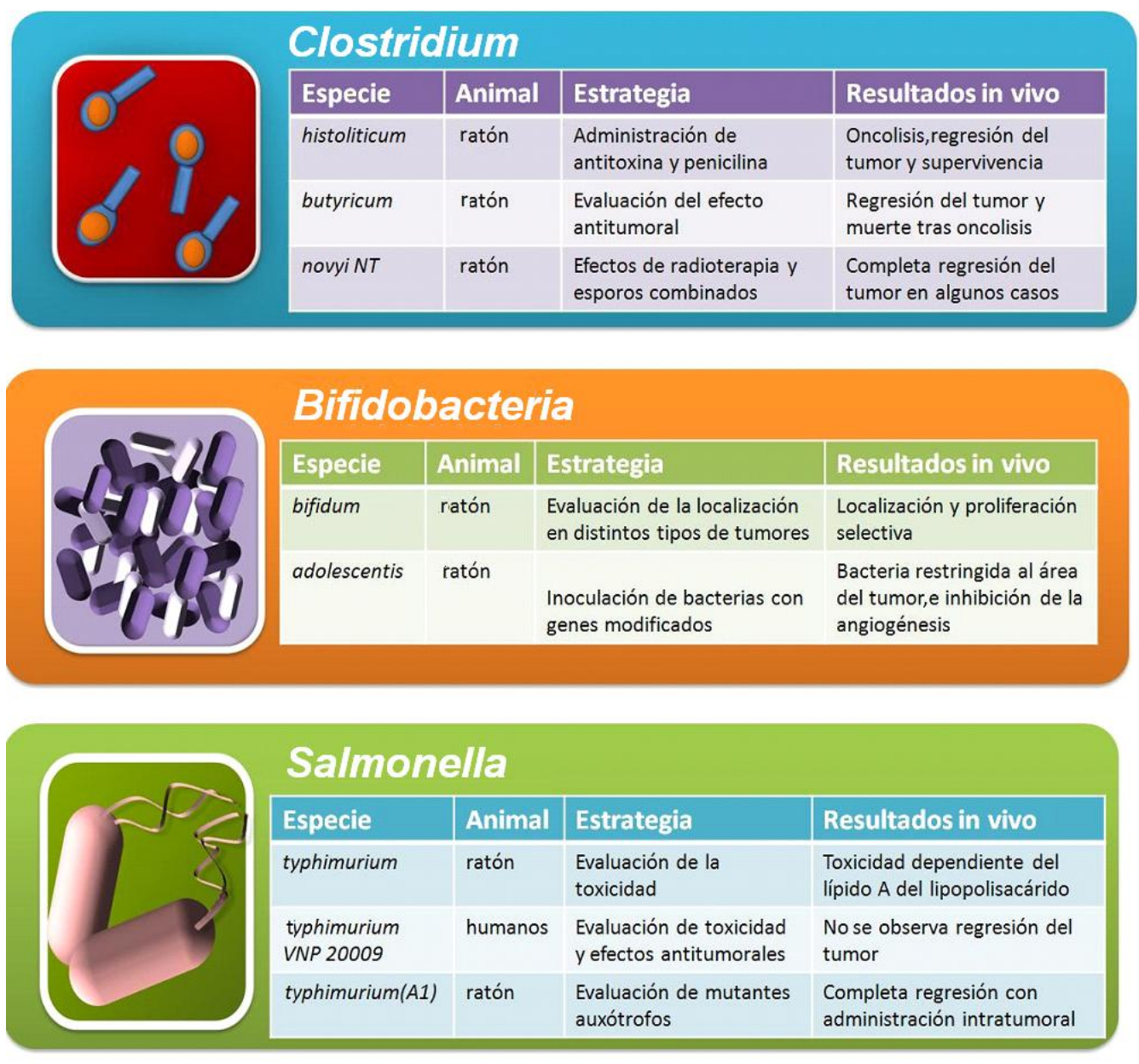

Figura 3: Principales géneros bacterianos investigados para tratamiento de tumores, estrategia para la cual fueron analizados y resultados obtenidos en las distintas especies. 


\section{ESPOROS BACTERIANOS}

Algunas bacterias gram positivas presentan la peculiaridad de formar esporos intracelulares cuando se presentan condiciones adversas frente a su crecimiento. Los esporos son formas de resistencia diferenciadas de las bacterias que los forman, altamente deshidratadas, contienen el genoma bacteriano completo y la maquinaria metabólica esencial, pero son formas criptobióticas, es decir, metabólicamente inertes. Se forman durante un complejo proceso de diferenciación denominado esporulación que comprende distintas etapas. Presentan gran capacidad de resistencia frente a radiaciones, productos químicos y temperaturas extremas, pudiendo permanecer en estado latente durante periodos de tiempo que pueden ser muy prolongados. Una vez que encuentran condiciones ambientales favorables, estas esporas germinan volviendo a la forma bacteriana vegetativa, la cual si es capaz de crecer y reproducirse, Vadillo et al. (2002).

Únicamente algunos géneros de bacterias gram positivas son capaces de formar esporos en su interior, y dentro de estos géneros las bacterias pueden pertenecer a diferentes grupos según, su fisiología (bacterias aerobias y anaerobias, quimiolitótrofas o fotótrofas), según su morfología (bacilos o cocos), así como según la localización del esporo en su interior (esporos centrales o subterminales).

Dentro de estas bacterias productoras de esporos y dependiendo de su tolerancia al oxigeno encontramos bacterias aerobias de tipo bacilar, géneros Bacillus spp. y Paenibacillus spp. y de morfología cocacea, género Sporosarcina spp. Mientras que entre las bacterias anaerobias se hallan géneros como, Anaerobacter spp., Halobacterium spp. o Clostridium spp. Este último género presenta ventajas respecto a los géneros anteriormente mencionados en la terapia frente a tumores sólidos, y va a determinar que sean muchas las investigaciones que se centran en su utilización.

\section{GÉNERO CLOSTRIDIUM}

Las bacterias del genero Clostridium son gram positivas, anaerobias estrictas y formadoras de esporos ante condiciones adversas. Actualmente este género está constituido por más de 100 especies, de las cuales aproximadamente 20 están asociadas a infecciones en los animales y el hombre, y por tanto son patógenas. El resto son inocuas, se encuentran ampliamente distribuidas en la naturaleza y algunas de ellas forman parte de la microbiota normal del tracto intestinal del hombre y los animales, Cerrato y Valle, (2002).

Son muchas las especies de clostridios que presentan ciertas características muy interesantes para su aplicación en biotecnología y microbiología industrial. Podemos destacar los productos terminales de su fermentación como butanol etanol, etc., González-Pajuelo et al., (2005), Lee et al., (2008), los enzimas producidos durante su metabolismo como celulasas, amilasas, hidrolasas etc., Shiratori et al., (2009), Calusinska et al., (2010) y la utilización de la toxina botulínica para tratamientos farmacológicos de la miriasis humana, Dhaked et al., (2010). 
Ahora bien, queremos destacar el papel importante que pueden desempeñar sus esporos, como vehículos de transporte de genes quimioterapéuticos para tratamiento de neoplasias.

\section{VENTAJAS DEL USO DE ESPOROS DE CLOSTRIDIUM COMO AGENTES TERAPÉUTICOS.}

Los esporos bacterianos cuentan con ciertas propiedades que suponen grandes ventajas, Ming et al., (2008a):

\section{A. SEGURIDAD}

Los esporos bacterianos pueden ser una opción terapéutica con menos riesgos, ya que no pueden germinar en condiciones aerobias, restringiendo su acumulación y germinación a zonas hipóxicas del tumor. Varios estudios con cepas no patógenas de Clostridium spp. han resultado seguros y en el caso de aparición de algún efecto no deseado, las bacterias pueden ser eliminadas de la sangre mediante antibióticos como metronidazol, Liu et al., (2002), Barbé et al., (2005).

\section{B. EJERCEN SU EFECTO SÓLO EN ÁREAS NEOPLÁSICAS}

Los esporos bacterianos son capaces de colonizar selectivamente los tumores sólidos, y sólo germinan en áreas anóxicas e hipóxicas, restringiendo su acción a estas zonas. Otros vectores no pueden replicarse en las células hipóxicas, por lo que esta característica de los esporos convierte a los tumores sólidos en una diana terapéutica.

\section{FÁCIL PRODUCCIÓN}

La producción de la mayoría de los tratamientos requiere sistemas sofisticados y caros. En cambio, la producción de esporos bacterianos es más sencilla y económica, además, pueden ser almacenados durante 3-6 meses.

\section{FÁCIL ADMINISTRACIÓN}

La mayoría de los agentes requieren ser administrados mediante una inyección intratumoral, con la desventaja de que muchos tumores se encuentran en zonas inaccesibles o de difícil punción. Los esporos se pueden administrar sistémicamente mediante inyección intravenosa y se dirigen selectivamente a las zonas hipóxicas.

\section{E. DESTRUCCIÓN DE TODO TIPO DE CÉLULAS TUMORALES}

Los tumores no sólo comprenden células malignas, también poseen matriz extracelular y otros tipos celulares no malignos, incluyendo fibroblastos, células del estroma, endoteliales e inflamatorias. El efecto antitumoral de los vectores bacterianos se basa en la producción de enzimas hidrolíticas (proteasas, nucleasas y lipasas) y en la competición entre la bacteria y las células neoplásicas por los nutrientes. Esta deprivación de nutrientes muchas veces causa la apoptosis de las células tumorales. Además de estos mecanismos, la transformación de los esporos en formas vegetativas activa el sistema inmune, induciendo efectos antitumorales. 


\section{F. SON AGENTES EXTRACELULARES.}

Los esporos bacterianos germinan y ejercen su acción independientemente de los mecanismos celulares y en el medio extracelular, evitando así la posibilidad de inducir mutagénesis al utilizar esporos de Clostridium spp. frente a otros agentes de carácter intracelular.

\section{G. POSIBILIDAD DE SER VECTORES DE GENES TERAPÉUTICOS.}

Sin duda una de las características más destacables es que estos agentes son susceptibles a ser modificados genéticamente con objeto de incorporarles genes terapéuticos. En el caso de los esporos de Clostridium spp., son muchas las investigaciones que han logrado incluir diversos genes y plásmidos, consiguiendo una capacidad ilimitada de insertar genes terapéuticos y mecanismos oncolíticos de acción selectiva en el tumor.

\section{H. RESUMEN}

Las principales características que presentan y que los caracteriza como agentes ideales se resumen en que los esporos son fáciles y económicos de producir y de almacenar al ser muy estables, pudiéndolos administrar por vía intravenosa, ofreciendo la posibilidad de ser utilizados como "caballo de Troya" de genes terapéuticos, habiéndose demostrado su seguridad en los tratamientos iniciales realizados en humanos, y mostrando efectos oncolíticos importantes, tanto en experimentos con animales como en intentos con humanos Ming et al., (2008b), Agrawai et al., (2004).

\section{INGENIERIA GENÉTICA PARA AUMENTAR LA CAPACIDAD DE ONCOLISIS TUMORAL}

Uno de los grandes problemas del uso de bacterias como agentes antitumorales es su toxicidad a la dosis requerida para obtener eficacia terapéutica, y que el hecho de disminuir la dosis para que esta toxicidad sea menor tiene como consecuencia una reducción de la efícacia. Ahora bien, el obstáculo básico en la terapia génica contra el cáncer es marcar específicamente la diana de la terapia directamente sobre el tumor sólido para evitar otros posibles efectos a nivel orgánico.

La colonización y crecimiento del microorganismo tiene la capacidad de provocar la destrucción de gran parte del tumor. Sin embargo, en estudios posteriores se demostró que podía ocurrir un recrecimiento tumoral desde el borde exterior, a partir de las células tumorales que aún se mantenían viables. Como consecuencia se concluyó que el tratamiento con esporos usando los clostridios "salvajes" no era suficiente para erradicar tumores sólidos, lo que llevó a cabo el planteamiento de estudios de otras alternativas en el uso de esporos de Clostridium como terapia frente al cáncer.

Una propuesta para superar estas limitaciones ha sido el uso de bacterias esporogénicas modificadas genéticamente para expresar un gen terapéutico específico. Produciendo la proteína de interés como consecuencia de la germinación del esporo específicamente en el 
microambiente tumoral. Estos vectores bacterianos pueden proporcionar una potente terapia adyuvante en varios tratamientos del cáncer. Las bacterias sirven como vectores o vehículos para proporcionar preferentemente agentes antitumorales, péptidos citotóxicos, proteínas terapéuticas o enzimas convertidoras de profármacos hacia los tumores sólidos.

\section{$\checkmark \quad T E R A P I A S$ DE ADN RECOMBINANTE}

Las terapias de ADN recombinante en bacterias se basan en la obtención de microorganismos con interés terapéutico aplicando técnicas de ingeniería genética, las cuales inducen la modificación de las secuencias de ADN originales de una bacteria al introducir en su código genético genes determinados. Para ello hay que aislar en primer lugar el gen que nos interesa, que posteriormente será integrado en el material genético de un plásmido (ADN extracromósomico con capacidad de replicación autónoma) mediante el uso de enzimas de restricción y enzimas ADNligasas. A continuación hay que introducir este plásmido en el interior de la bacteria, generalmente por transformación, mediante la utilización de diversas metodologías como son la aplicación de métodos químicos como el cloruro cálcico, o métodos físicos tales como la electroporación o también llamada electropermeabilización. Una vez creada la bacteria recombinante, se cultiva en condiciones específicas para que produzca esporos. Estos incluyen todo el ADN de la bacteria de la que proceden.

El primer clostridio en ser genéticamente modificado fue $C$. oncolyticum. Se le incluyó en su genoma un plásmido recombinado con el gen que codifica la Colicina E3, perteneciente a E.coli, Schlechte y Elbe, (1988), una bacteriocina que ha mostrado tener efectos cancerostáticos aparte de acción antimicrobiana. Sin embargo los resultados obtenidos acerca de la eficacia de esta bacteriocina no fueron concluyentes, se cree que como consecuencia de la metodología de modificación genética empleada en tal caso, que posteriormente fue mejorada mediante la aplicación de electroporación.

Ahora bien, dentro de estas técnicas debemos destacar la tecnología que aborda la inclusión de genes terapéuticos que codifican para enzimas pro-fármaco.

Gene-directed-enzyme-prodrug therapy (GDEPT) (Terapia génica dirigida para enzima prodroga)

Esta estrategia consiste en el uso de bacterias esporogénicas anaerobias transformadas genéticamente al introducir un gen que codifica para una enzima que lleva a cabo la conversión de forma específica de un fármaco no tóxico o profármaco administrado sistémicamente en un fármaco tóxico para las células tumorales. Esta enzima sería expresada únicamente en el tumor tras la proliferación de la bacteria a su forma vegetativa en las áreas necróticas e hipóxicas, dando como resultado de la acción oncolítica del fármaco tóxico, la destrucción del tumor sin afectar al resto del organismo (Fig. 4). 


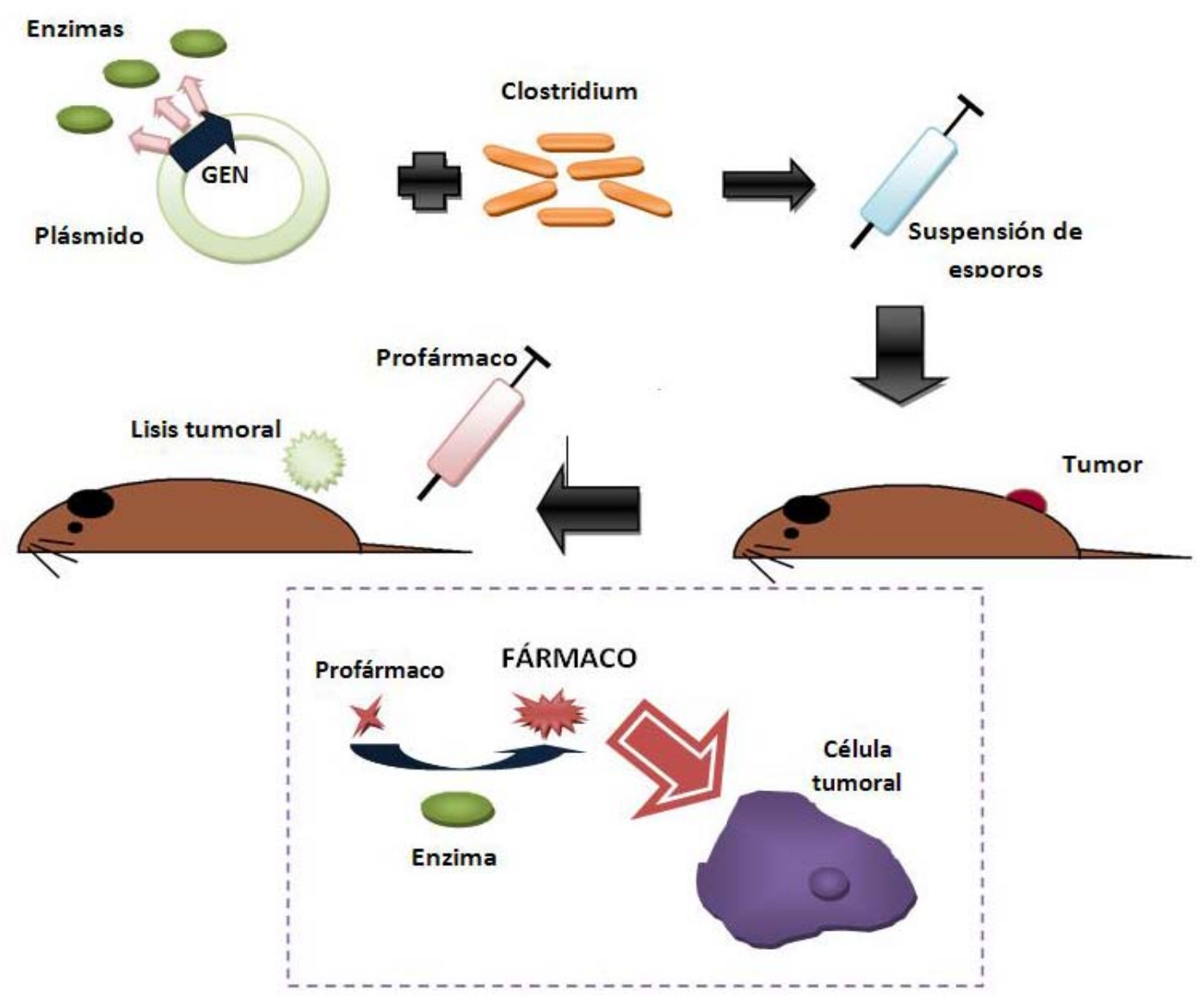

Figura 4: Representación esquemática de Gene-directed-enzyme-produg therapy (GDEPT), basada en la inserción de plásmidos con determinados genes en bacterias, que codifiquen enzimas implicadas en la formación de fármacos oncolíticos tras la previa aplicación de un profármaco inocuo.

Se han realizado diversos estudios para la formación de esporos recombinantes con cepas sacarolíticas de Clostridium (C. beijerinckii, C. acetobutylicum, C. butyricum), que se centraron en la inserción de plásmidos con genes de $E$. coli que codificaran para una determinada enzima pro-fármaco. Uno de los genes que ha sido probado es el gen codA que codifica para la síntesis de la enzima bacteriana Citosina Deaminasa (CD-asa) que convierte el compuesto aplicado por vía sistémica 5-fluorocitosina $(5 \mathrm{FC})$ en otro compuesto tóxico antitumoral, el 5-fluoracilo (5FU), que inhibe la síntesis de ADN y ARN resultando por lo tanto la disrupción de la síntesis proteica en las células tumorales, Fox et al., (1996). También se ha estudiado la inserción del gen que codifica para la Nitroreductasa (NTR), Minton et al., (1995), Lemmon et al., (1997), que convierte la prodroga CB1954 en un derivado 10.000 veces más tóxico, la 4-hidroxilamina (4HX) que causa el entrecruzamiento del ADN e induce apoptosis, Knox et al., (1988, 1993).

Pese a que en el estudio de estas recombinaciones in vitro se conseguía una elevada concentración de estas enzimas en los modelos tumorales y el consiguiente resultado de lisis tumoral, hasta la fecha los resultados in vivo han sido decepcionantes al no conseguir un 
control del crecimiento tumoral. Así mismo, estos resultados desfavorables se observaban en mayor medida cuando los esporos recombinantes se administraban vía sistémica en comparación de lo que ocurría cuando se administraban intratumoralmente. El factor que puede haber contribuido a esta falta de eficacia puede haber sido un bajo nivel de colonización bacteriana con una insuficiente expresión de genes recombinantes y una consecuente secreción enzimática insuficiente en el tumor, Wei et al., (2008).

Sin embargo, con respecto a los clostridios previamente mencionados, la cepa sacarolítica $C$. sporogenes presenta una mayor capacidad de colonización tumoral probablemente como consecuencia de su carácter proteolítico, pero pese a sus potentes propiedades oncolíticas no es capaz de eliminar el tumor eficientemente. Por esto se construyeron esporos recombinados con la introducción de genes de la citosina deaminasa de E. coli en C. sporogenes, Lemmon et al., (1997), Liu et al., (2002). En este caso, la inyección intravenosa seguida por la administración del pro-fármaco 5-FC mostraba un significante efecto antitumoral in vivo, aunque por causas desconocidas esta inhibición del crecimiento tumoral no persistía en el tiempo. También existen estudios a cerca de la introducción de plásmidos mediante conjugación, que contienen el gen de la Nitrorreductasa (NTR) en C. sporogenes, siendo positivos los resultados obtenidos al mostrar significantes efectos anti tumorales in vivo en combinación a la administración de la pro-droga, Theys et al., (2006).

En un intento de incrementar la especificidad y eficacia de las terapias génicas con Clostridium se han estudiado alternativas al GDEPT. Se han creado esporos recombinantes de C. acetobutilycum genéticamente modificados para secretar el factor de necrosis tumoral alfa (mTNF $\alpha)$, Theys et al., (1999, 2001), una citoquina biológicamente activa con múltiples efectos antitumorales, incluyendo efectos sobre la neovascularización tumoral, estimulación de la inmunidad mediada por linfocitos $\mathrm{T}$ y una citotoxicidad directa sobre las células tumorales principalmente mediante la inducción de apoptosis. El mTNFa presenta amplios efectos colaterales cuando es administrado sistémicamente, por lo que mediante este sistema se busca disminuir su toxicidad y aumentar su eficacia debido al crecimiento que se restringiría únicamente a las áreas tumorales donde germinarían los esporos modificados para secretar esta citoquina.

Así mismo, se ha estudiado la incorporación de la interleukina-2 de rata (rIL-2) en C. acetobutilycum, Barbé et al., (2005). Esta citoquina realza la respuesta inmune inespecífica, la estimulación de la actividad citotóxica de las células asesinas naturales (NK= natural killer) y macrófagos, la respuesta inmune específica mediada por linfocitos $\mathrm{T}$ al reconocer antígenos tumorales, y el aumento de citoquinas secundarias por parte de linfocitos activados, resultando todas estas acciones importantes para la lisis de células tumorales. Sin embargo, la utilidad de la rIL-2 usada como única terapia es escasa, obteniendo una mayor actividad antitumoral al combinarla con otras citoquinas o con otros tratamientos como pueden ser la quimioterapia o radioterapia. 


\section{TRATAMIENTO CON CLOSTRIDIUM}

Como consecuencia del hallazgo casual de Vautier, se han realizado numerosos experimentos en este sentido, consiguiendo demostrar que no fue algo fortuito, sino que efectivamente hay una clara evidencia de que las formas esporuladas de Clostridium germinan de forma específica en el tumor.

\section{- INVESTIGACIÓN BÁSICA EN ANIMALES DE EXPERIMENTACIÓN}

Los primeros experimentos que se llevaron a cabo fueron los realizados en 1927 por Torrey y Kahn, en 1935 por Connell y en 1947 por Parker y colaboradores, citados por Barbé et al., (2006) y Wei et al., (2008). En las investigaciones realizadas por Connell y Parker se administraron intratumoralmente una suspensión de esporos Clostridium histolyticus en ratones a los que se habían trasplantado sarcomas. Ambos grupos obtuvieron el mismo resultado: regresión tumoral y aumento del tiempo de supervivencia de los ratones enfermos. No obstante, no consiguieron una regresión tumoral completa, sino que quedaban células viables que provocaban el recrecimiento tumoral. Como consecuencia, se estableció la necesidad de buscar cepas de Clostridium con mayor potencial oncolítico, así como la posibilidad de combinar el tratamiento utilizando Clostridium con otros tratamientos convencionales.

Años más tarde, se consiguió demostrar que no era necesaria la administración intratumoral, sino que una administración intravenosa era igualmente efectiva, ya que el esporo tenía la capacidad de dirigirse de forma específica al tejido neoplásico y únicamente germinar en dicho microambiente. Los primeros en demostrar el efecto fueron Malgrem y Flanigan en 1955, citados por Barbé et al. (2006) y Wei et al. (2008). Dichos investigadores utilizaron una suspensión de Clostridium tetani sobre ratones con carcinomas mamarios espontáneos, carcinomas mamarios inducidos, hematomas, fibrosarcomas y ratones libres de tumor. Efectivamente, la administración intravenosa en ratones con carcinomas mamarios dio como resultado la regresión tumoral, pero a las 48 horas, todos los ratones enfermos morían como consecuencia de las toxinas (neurotoxinas) que liberaba la bacteria al germinar. En cambio, en los ratones libres de tumor no se producía ningún efecto secundario, ya que la bacteria no germinaba en ningún momento.

En 1964 Möse y Möse, citados por Barbé et al., (2006) y Wei et al., (2008), para evitar las consecuencias fatales que se producían con Clostridium tetani, experimentaron con una especie benigna. Con la misma metodología, administraron vía intravenosa una suspensión de Clostridium butyricum M55 a ratones con carcinomas sólidos de Erhlich. Ahora bien, a pesar de ser una bacteria no patógena, la extensa oncolisis provocó en la mayoría de los animales la muerte, y en los que consiguieron sobrevivir se observaba remisión tumoral incompleta, quedando células viables que inducían que el tumor reapareciera (Tabla 1). 


\begin{tabular}{|c|c|c|}
\hline $\begin{array}{c}\text { Connell (1935) / Parker } \\
\text { et al. (1947) }\end{array}$ & $\begin{array}{l}\text { Malgrem y Flanigan } \\
\qquad(1955)\end{array}$ & Möse y Möse (1964) \\
\hline $\begin{array}{l}\text { Administración } \\
\text { intratumoral de C. } \\
\text { histolyticum } \\
\text { Regresión tumoral } \\
\text { incompleta } \\
\text { (recrecimiento } \\
\text { tumoral) }\end{array}$ & $\begin{array}{l}\text { Administración } \\
\text { intravenosa de } C \text {. } \\
\text { tetani } \\
\text { - Regresión tumoral } \\
\text { Muerte en ratones } \\
\text { con tumor a las } 48 \\
\text { horas (por las } \\
\text { neurotoxinas de la } \\
\text { bacteria) }\end{array}$ & $\begin{array}{l}\text { Administración } \\
\text { intravenosa de C. } \\
\text { sporogenes ATCC } \\
13732 \\
\text { - Regresión tumoral } \\
\text { incompleta } \\
\text { - Muerte en la } \\
\text { mayoría de los } \\
\text { ratones como } \\
\text { consecuencia de la } \\
\text { extensa oncolisis }\end{array}$ \\
\hline
\end{tabular}

Tabla 1: Experimentos de mayor relevancia en animales de laboratorio, donde se incluye la especie de Clostridium empleada, vía de administración, efecto sobre el tumor y reacciones adversas sobre los animales.

Posteriormente en 1998 el grupo de investigación liderado por Lambin, citados por Ryan et al. (2005) y por Barbé et al. (2006), descubrieron que en general Clostridium sólo era efectivo frente a tumores de un tamaño moderadamente grande $\left(3 \mathrm{~cm}^{3}\right)$, siendo totalmente ineficaz contra las metástasis que fueran menores de 2-4 gramos. Esto es debido a que los tumores pequeños no eran colonizados, como consecuencia de la limitada hipoxia y la pequeña o ausente necrosis si los comparamos con tumores de mayor talla.

\section{- EXPERIMENTOS EN MEDICINA VETERINARIA}

Las especies domésticas sobre las que se centraron diversos estudios fueron tres: cánidos, ganado bovino y équidos realizados por Dietz et al., (1980), Wittmann et al., (1990) y Fabricius et al., (1994), citados por Sdhmidt et al., (2006).

Los experimentos realizados en medicina veterinaria se basaron en la utilización de test serológicos en los que se medía la producción de anticuerpos frente a Clostridium una vez que se producía la germinación, los cuales, evidentemente, eran diferentes de los anticuerpos frente a los esporos de Clostridium. Ahora bien, estos ensayos clínicos no tenían como propósito estudiar las posibilidades terapéuticas de Clostridium utilizado como agente antineoplásico, sino que su objetivo era determinar las ventajas de utilizarlos como indicadores que permitieran llevar a cabo un diagnóstico precoz de procesos tumorales respecto a procesos no tumorales. Asimismo el test pretendía medir de forma indirecta el tamaño tumoral, ya que cuanto mayor fuera el tumor, mayor cantidad de bacterias habrían germinado y por tanto mayor número de anticuerpos anticlostridium se podrían hallar. 
La metodología utilizada por Dietz et al., (1980) en perros fue la siguiente (Fig.5): en primer lugar se tomaban muestras de sangre para tener una referencia previa al tratamiento, después se administró $2 \times 10^{8}$ esporos de Clostridium butyricum CNRZ 528 vía intravenosa. A los 1014 días el tumor se operaba, y de nuevo se tomaban muestras de sangre entre la primera y segunda semana, y entre la tercera y cuarta después de la cirugía. Las tomas seriadas de sangre se realizaban para poder comparar resultados antes y después de la cirugía. El objetivo concreto era valorar si se producía crecimiento tumoral tras la cirugía, mediante la medición de los anticuerpos anticlostridium. ¿Cómo se realizaba la valoración?: en caso de recrecimiento, los esporos administrados dispondrían de un lugar con las características adecuadas para su germinación, lo que provocaría una proliferación de formas vegetativas y en consecuencia una marcada respuesta serológica. En cambio, si la cirugía había sido efectiva y se había conseguido extirpar por completo el tumor, al no haber crecimiento tumoral, los esporos no germinarían y por tanto el número de anticuerpos anticlostridio se correspondería con el de la toma de sangre previa a la cirugía, no habiendo un aumento significativo.

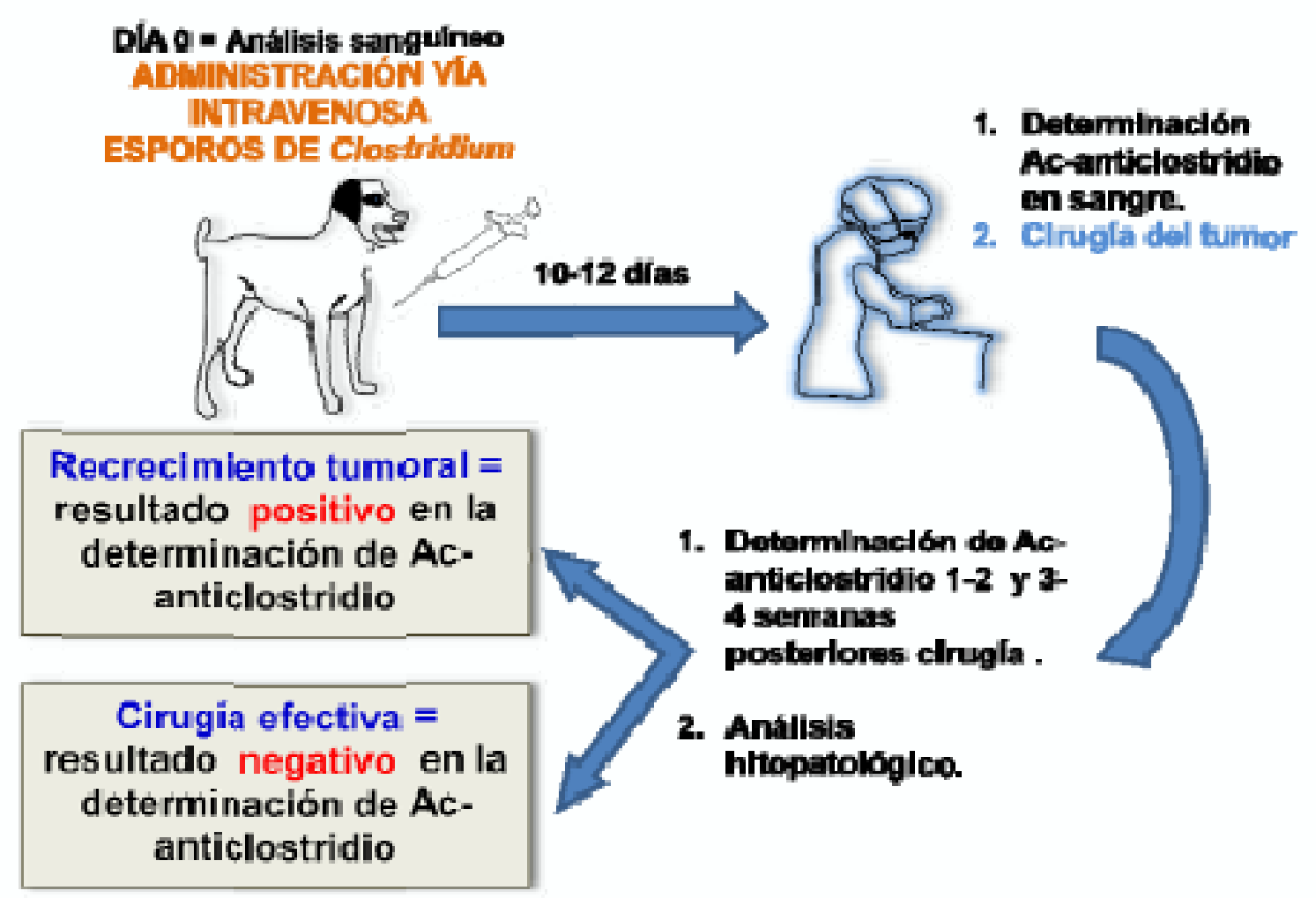

Figura 5: Representación esquemática de la metodología empleada, Dietz et al., (1980), en el estudio de la remisión de tumores en cánidos utilizando esporos de Clostridium butyricum CNRZ 528. 
En los sucesivos experimentos en medicina veterinaria la cepa utilizada ha sido Clostridium butyricum CNRZ 528, que presenta poder sacarolítico, no es patógena y está aislada del queso, por lo tanto su utilización no entrañaba riesgo. Los ensayos se realizaron en el "Saxonian Serum Institute Dresden" por Fabricious et al., (1987) sobre un total de 251 perros, de los cuales 153 presentaban tumores malignos, 59 tumores benignos y 39 eran controles. En el ensayo se realizó evaluación histopatológica independiente del serodiagnóstico y viceversa, con el objetivo de evaluar los datos de forma multivariante. Los resultados permitieron concluir que el test serológico presentaba una eficacia de diagnóstico de un 80-70\%.

Estudios semejantes a los anteriores fueron realizados en bóvidos por Wittmann et al., (1990) y en équidos por Fabricious et al., (1994).

Sin duda, la investigación en tumores espontáneos en animales anticipa nuevas opciones en patología comparada y da la oportunidad de ganar experiencia para estudios clínicos en oncología humana.

\section{COMBINACIÓN CON OTRAS TERAPIAS}

Para entender cuál es el motivo que nos lleva a estudiar la posibilidad de combinar el uso de Clostridium con terapias convencionales partimos de tres conceptos fundamentales (Fig. 6):

1) Clostridium es capaz de destruir las zonas hipóxicas del tumor, pero no las zonas bien irrigadas, Ryan et al., (2005).

2) Las dosis de radioterapia necesaria para células hipóxicas supone el triple de la dosis necesaria para dañar células bien oxigenadas, Moeller et al., (2007).

3) Los agentes quimioterápicos actúan fundamentalmente sobre células mitóticamente activas. Las células hipóxicas, debido a la falta de oxígeno y nutrientes, tienen una menor tasa de crecimiento y por tanto su proliferación es menor, lo que da lugar a que la quimioterapia no sea muy efectiva, Brown (2002). 


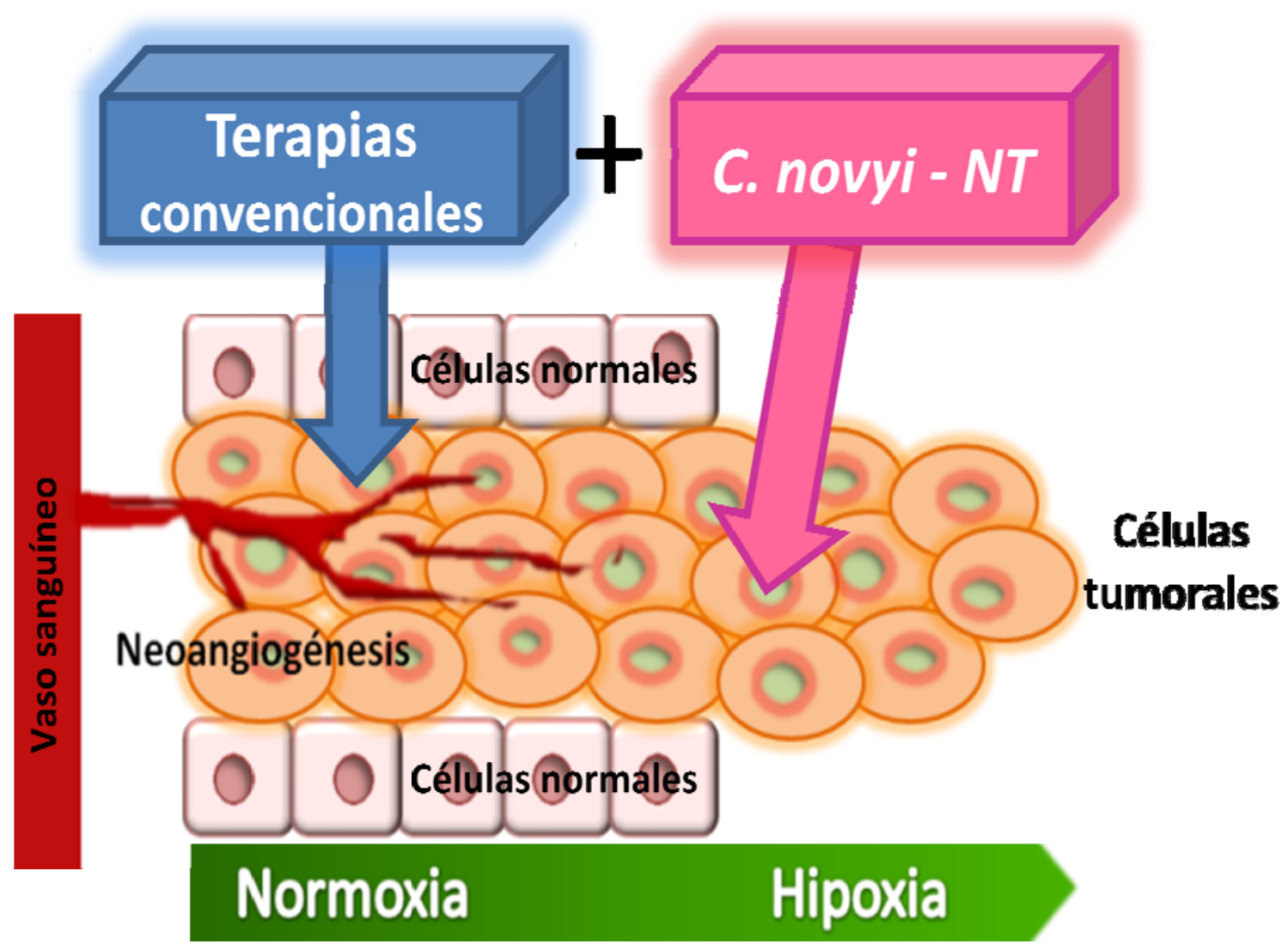

Figura 6: Esquema sobre las bases de la actuación de la terapia combinada (terapias convencionales + Clostridium novyi-NT) en la resolución de tumores.

Por tanto, el uso combinado de esporos con radioterapia y quimioterapia permite, en primer lugar, disminuir la dosis requerida de radiación en radioterapia (ya que no es necesario que la radiación destruya las células hipóxicas, que serán atacadas por Clostridium) y por otro lado aumenta la eficacia respecto al uso aislado de agentes quimioterápicos, ya que las células menos activas mitóticamente son destruidas por Clostridium y las activas mitóticamente son destruidas por el agente quimioterápico empleado.

Las terapias combinadas que más se han investigado son:

\section{$\checkmark$ Quimioterapia convencional y Clostridium}

La combinación de estas dos técnicas terapéuticas permite atacar el tumor en toda su extensión, ya que el agente quimioterápico es eficaz frente a la región oxigenada, y Clostridium frente a las regiones hipóxicas. No obstante, no resulta útil para tratar micrometástasis, ya que la región hipóxica de estas es mínima.

Las primeras investigaciones fueron llevadas a cabo por Dang et al., (2001) en ratones de experimentación con tumores colorrectales HTC 116. En el protocolo de trabajo utilizaron el quimioterápico mitomicina $\mathrm{C}$, esporos de una cepa modificada 
genéticamente de Clostridium novyi, a la que llamaron Clostridium novyi - NT ("Non Toxic") y el agente antivascular dolastatina 10. Este último evitaba que se produjese revascularización en el tumor, y además permitía incrementar las regiones hipóxicas, ya que interrumpía la red vascular. A esta terapia combinada le pusieron el nombre de COBALT ("Combination Bacteriolythic Therapy").

En este primer ensayo los datos obtenidos resultaron ser relativamente esperanzadores, ya que aproximadamente el $15 \%$ de animales con tumores con un volumen de 350 $\mathrm{mm}^{3}$ y el $45 \%$ de animales con tumores más grandes morían en un intervalo de tiempo de 24 a $48 \mathrm{~h}$ tras recibir el tratamiento. Estas mortalidades se producían como consecuencia de los altos efectos antineoplásicos ligados a COBALT, puesto que inducía una rápida y amplia destrucción de tumores de gran tamaño (síndrome de lisis tumoral). Hay que indicar que en los ratones que conseguían sobrevivir, se observó una disminución del tamaño del tumor en un periodo de 2 a 4 semanas y posteriormente la desaparición completa del mismo.

Con el objeto de valorar la utilización de esporos de C. novyi - NT desde un punto de vista farmacológico y toxicológico, integrantes del grupo investigador anterior administraron grandes dosis de esporos $\left(500 \times 10^{6}, 5000 \times 10^{6}\right.$ y $25000 \times 10^{6}$ esporos $\left./ \mathrm{Kg}\right)$ a ratones BALB/c y conejos New Zeland. Dichos autores no observaron toxicidad clínica ni en animales sanos, ni en aquellos que albergaban lesiones pobremente vascularizadas no neoplasicas, anteriores a la dosificación, tales como infartos de miocardio, Diaz et al., (2005).

\section{$\checkmark$ Radioterapia y Clostridium}

La combinación de agentes radiactivos y Clostridium permite reducir la dosis requerida de radiación y aumentar la eficacia terapéutica.

Los primeros que experimentaron este tipo terapia combinada fueron Bettegowda et al., (2003). Estos autores utilizaron ratones de experimentación a los que se les indujo diferentes tipos de tumoración: cáncer colorrectal HTC116, cáncer biliar humano HuCC-TI, melanoma de rarón B16, carcinoma de células escamosas de conejo VX2, etc. Para el tratamiento emplearon dos tipos de radioterapia (radioterapia de haz externo y braquiterapia) combinados con esporos de Clostridium novyi-NT.

Los resultados obtenidos mediante la combinación de radioterapia de haz externo, demostraron que el tratamiento combinado mejoraba los efectos respecto de ambas técnicas utilizadas de forma aislada. Sin embargo, no se producía la eliminación de todas las células tumorales, por lo que en la mayoría de los casos se producía recrecimiento tumoral. Con estos datos concluyeron que eran necesarias dosis mayores de radiación para conseguir eliminar todas las células neoplásicas; ahora bien, dichas dosis resultan letales. 
La otra modalidad de radioterapia utilizada fue la braquiterapia, en la que se coloca material radiactivo dentro del tumor y tejido circundante, permitiendo incrementar las dosis de radiación sin que se produzcan los efectos negativos anteriores. Su dosificación combinada con la administración de 300 millones de esporos de Clostridium Novyi-NT suspendidos en $550 \mu \mathrm{l}$ de PBS en cada animal, demostró una alta eficacia, ya que permitió la curación de todos los animales utilizados.

\section{$\checkmark$ Proteinas antivasculares y Clostridium}

Esta terapia combinada pretende aumentar la eficacia de Clostridium, ya que las proteínas antivasculares, mediante el bloqueo del aporte sanguíneo, consiguen incrementar las regiones hipóxicas del tumor.

El equipo de investigación de Theys et al., (2001) fueron los iniciadores de este tipo de terapia tumoral. En el experimento utilizaron el agente antivascular combrestatina A4 Fosfato y $10^{8}$ esporos de Clostridium sporogenes sobre ratones a los que se les había inducido rhabdomiosarcomas subcutáneos.

El resultado fue un incremento de la regresión tumoral, mayor en tumores de gran tamaño (7-14 $\left.\mathrm{cm}^{3}\right)$, que el observado en tumores de menor talla, que demostraba la mayor eficacia de la terapia combinada frente a la administración única de Clostridium.

\section{$\checkmark$ Agentes que interaccionan con los microtubulos celulares y Clostridium}

Varios investigadores respaldan la utilización de una combinación de agentes antimicrotubulos, utilizados para tratamiento de diversos tumores (vinorelvina y el HTI286) y esporos de Clostridium novyi-NT (300 x 106), Dang et al., (2001, 2004), ocasionando la destrucción tanto de los compartimentos vascularizados como los no vascularizados de tumores.

En este mismo sentido, Smith et al., (2005) han ensayado terapia tumoral con un potente agente inhibidor del crecimiento celular, la discodermolida, aislada de la esponja marina Discodermia dissoluta, y esporos de Clostridium novyi-NT. Los resultados han podido demostrar que este tratamiento combinado ocasionaba una rápida y completa regresión de cáncer colorrectal HCT116 en ratones de laboratorio (Fig.6).

\section{$\checkmark$ Quimioterapia cancerígena liposomal y Clostridium}

El Clostridium novyi-NT presenta enzimas capaces de lisar eritrocitos. Teniendo en cuenta esta característica, Cheong et al., (2006) proponen el tratamiento conjunto con quimioterápicos encapsulados de forma liposomal (concretamente doxorubicina liposomal), reduciendo la toxicidad que provoca el medicamento. Su hipótesis se basa en el hecho de que estas enzimas provocarían la disrupción de las capas lipídicas que envuelven al quimioterápico. Los resultados obtenidos son esperanzadores ya que 
consiguieron una menor toxicidad en los animales y una reducción seis veces superior a la administración del quimioterápico solo.

\section{CONCLUSIONES Y PERSPECTIVAS DE FUTURO}

Las terapias tradicionales contra el cáncer siguen siendo poco efectivas, sobre todo si van dirigidas al tratamiento de tumores secundarios. No obstante, se ha comprobado que los microorganismos pueden constituir una buena alternativa, ya que tienen gran potencial como agentes antineoplásicos, debido tanto a su actividad oncolítica como a su capacidad de penetrar en zonas inaccesibles del tumor.

El caso particular del uso de esporos de Clostridium spp. presenta un interesante potencial frente a tumores que contengan amplias regiones anóxicas e hipóxicas. El efecto antitumoral es consecuencia o bien del efecto innato de la cepa utilizada, que da lugar a la producción de proteasas y lipasas, o bien de la modificación de una cepa produciéndose una enzima convertidora de prodrogas o una citoquina. Su eficacia abre una nueva perspectiva en el tratamiento de tumores sólidos, sobre todo en combinación con otros tratamientos.

Ahora bien, en la actualidad resulta necesario resolver algunas cuestiones:

- aumentar la colonización tumoral y disminuir la dosis tóxica.

- reducir la toxicidad sistémica tras oncolisis muy extensas (Síndrome de lisis tumoral).

- adecuar el tratamiento para tumores de menos talla, y en metástasis.

\section{AGRADECIMIENTOS:}

Dra. Esperanza Gómez-Lucía Duato. Dpto de Sanidad Animal, Facultad de Veterinaria de la Universidad Complutense de Madrid (España), por su inestimable ayuda en la revisión del manuscrito final.

\section{BIBLIOGRAFIA}

Agrawal, N., Bettegowda, Ch., Cheong, I., Geschwind, JF., Drake, Ch., Hipkiss, E., Tatsumi, M., Dang, LH., Pomper, M., Abusedra, M., Wahl, RL., Kinzler, KW., Zhou, Sh., Huso, DL. y Vogelstein, B. (2004). Bacteriolytic therapy can generate a potent immune response against experimental tumors. Proc. Natl. Acad. Sci. USA. 101(42): 15172-15177. doi: $10.1073 /$ pnas.0406242101

Barbé, S., Van Mellaert, L., Theys, J., Geukens, N., Lammertyn, E., Lambin, P. y Anné, J. (2005). Secretory production of biologically active rat interleukin-2 by Clostridium acetobutylicum DSM792 as a tool for anti-tumor treatment. FEMS Microbiol. Let. 246, 6773

Barbé, S., Van Mellaert, L. y Anné J. (2006). The use of clostridial spores for cancer 
treatment. J. Appl. Microbiol. 101:571-578. doi: 10.1111/j.1365-2672.2006.02886.x

Bettegowda, Ch., Dang, LH., Abrams, R., Huso, DL., Dillehay, L., Cheong, I., Agrawai, N., Borzillary, S., MacCaffery, M., Watson, EL., Lin KSh., Bunz, F., Baidoo, K., Pomper, MG., Kinzler KW., Volgelstein, B. y Zhou Sh. (2003). Overcoming the hypoxic barrier to radiation therapy with anaerobic bacteria. Proc. Natl. Acad. Sci. USA. 11 (25): 15083-15088. doi: $10.1073 /$ pnas.0406242101

Bickels, J., Kollender, Y., Merinsky, O. y Meller, I. (2002). Coley's toxin: Historical Perspective. Isr. Med. Assoc. J. 4: 471-472.

Brook, I. (2007). Microbiology and management of infected solid tumours. Europ. J. Cancer Care 16: 12-16. doi: $10.1111 / \mathrm{j} .1365-2354.2006 .00706 . \mathrm{x}$

Brown, JM. (2002). Tumor microenvironment and the response to anticancer therapy. Cancer Biol. Ther. September-October 1(5): 453-458. http://dx.doi.org/10.4161/cbt.1.5.157

Diaz LA Jr., Cheong I., Foss CA., Zhang X., Peters BA., Agrawal N., Bettegowda C., Karim B., Liu G., Khan K., Huang X., Kohli M., Dang LH., Hwang P., Vogelstein A., Garrett-Mayer E., Kobrin B., Pomper M., Zhou S., Kinzler KW., Vogelstein B. y Huso DL. (2005). Pharmacologic and Toxicologic Evaluation of C. novyi-NT Spores. Toxicol Sci December 88(2):562-75. doi: 10.1093/toxsci/kfi316

Dang LH., Bettegowda C., Huso DL., Kinzler KW. y Vogelstein B. (2001). Combination bacteriolytic therapy for the treatment of experimental tumours. Proc. Natl. Acad. Sci. vol 98, (26): 15155-15160. doi: 10.1073/pnas.251543698

Fox ME., Lemmon MJ. y Mauchline ML. (1996). Anaerobic bacteria as a delivery system for cancer gene therapy: in vitro activation of 5-fluorocytosine by genetically engineered clostridia. Gene Therapy 3: 173-178

Lemmon MJ., van Zijl P., Fox ME., Mauchline ML., Giaccia AJ., Minton NP y Brown JM. (1997). Anaerobic bacteria as a gene delivery system that is controlled by the tumor microenvironment. Gene Therapy 4: 791-796.

Liu SC., Minton NP., Giaccia AJ. y Minton NP. (2002). Anticancer efficacy of systemically delivered anaerobic bacteria as gene therapy vectors targeting tumor hypoxia/necrosis. Gene therapy 9: 291-296

Kizaka-Kondoh S., Inoue M., Harada H. y Hiraoka M. (2003) Tumor hipoxia: A target for selective cancer therapy. Cancer Sci December 94(12): 1021-1028. doi: 10.1111/j.13497006.2003.tb01395.x

Knox RJ., Friedlos F., Jarman M. y Roberts JJ. (1988) A new cytotoxic, DNA interstrand crosslinking agent, 5-(aziridin-1-yl)-4-hydroxylamino-2-nitrobenzamide, is formed from 5(aziridin-1-yl)-2,4-dinitrobenzamide (CB 1954) by a nitroreductase enzyme in Walker carcinoma cells. Biochem Pharmacol. December 15; 37 (24): 4661-4669. http://dx.doi.org/10.1016/0006-2952(88)90335-8

Knox RJ., Friedlos F. y Boland MP. (1993). The bioactivation of CB 1954 and its use as a prodrug in antibody-directed enzyme prodrug therapy (ADEPT). Cancer Metastasis Rev 
12: $195-212$.

Minton NP., Mauchline ML. y Lemmon MJ. (1995). Chemotherapeutic tumour targeting using clostridial spores. FEMS Microbiol Rev 17: 357-364

Patyar S., Joshi R., Byrav DSP., Prakash A., Medhi D. y Das BK. (2010). Bacteria in cancer therapy: a novel experimental strategy. J Biomed Sci Mar 23; 17 (1) 2: 1-9. doi: $\underline{10.1186 / 1423-0127-17-21}$

Ryan R.M., Green J. y Lewis CE. (2005) Use of bacteria in anti-cancer therapies. Bio Essays 28: 84-94. doi: $10.1002 /$ bies.20336

Schmidt W., Fabricius E.M. y Schneeweiss U. (2006). The tumour-Clostridium phenomenon: 50 years of developmental research. International journal of oncology 29: $1479-1492$

Theys J., Nuyts S., Landuyt W., Van Mellaert L., Dillen C., Böhringer M., Dürre P. y Lambin P. (1999). Stable Escherichia Coli-Clostridium acetobutylicum shuttle vector for secretion of murine tumor necrosis factor alpha. Appl Environ Microbiol 65: 4295-4300

Theys J., Landuyt W., Nuyts S., Van Mellaert L., Lambin P. y Anné J. (2001). Clostridium as a tumor-specific delivery system of therapeutic proteins. Cancer Detect Prev 25: 548557

Theys J., Pennington O., Dubois L., Anlezark G., Vaughan T., Mengesha A., Launduyt W., Anne J., Burke PJ., Durre P., Wouters BG., Minton NP. y Lambin P. (2006). Repeated cycles of Clostridium-directed enzyme prodrug therapy result in sustained antitumour effects in vivo. British Journal Cancer 95: 1212-1219. doi: 10.1038/sj.bjc.6603367

Trédan O., Grantab R. y Dumontet Ch. (2008) L'hypoxie tumorale peut-elle devenir un avantage pour la chimiothérapie. Bull Cancer; 95(5): 528-34. doi: 10.1684/bdc.2008.0637

Van Mellaert L., Barbé S. y Anné J. (2006) Clostridium spores as anti-tumour agents. Trends Microbiol. April; 14 (4): 190-196. http://dx.doi.org/10.1016/j.tim.2006.02.002,

Wei MQ., Ellem AOK., Dunn P., West MJ., Bai ChX. y Vogelstein B. (2007) Facultative or obligate anaerobic bacteria have the potential for multimodality therapy of solid tumours. European. J. Cancer 43 490-496. http://dx.doi.org/10.1016/j.ejca.2006.10.005,

Wei MQ., Mengesha A., Good D. y Anné J. (2008a). Bacterial targeted tumour theraphydawn of a new era. Cancer Let. 259:16-27. http://dx.doi.org/10.1016/j.canlet.2007.10.034,

Wei MQ., Ren R., Good D. y Anné J. (2008b) Clostridial spores as live "Trojan horse" vectors for cancer gene therapy: comparison with viral delivery systems. doi: $10.1186 / 1479-$ 0556-6-8 